Check for updates

Cite this: RSC Adv., 2021, 11, 2643

Received 1st November 2020

Accepted 17th December 2020

DOI: $10.1039 / \mathrm{d}$ Ora09298c

rsc.li/rsc-advances

\section{Cobalt metal-organic framework-based ZIF-67 for the trace determination of herbicide molinate by ion mobility spectrometry: investigation of different morphologies $\dagger$}

\author{
Mehdi Davoodi, ${ }^{a}$ Fatemeh Davar, ${ }^{\star a}$ Mohammad R. Rezayat, ${ }^{a}$ Mohammad T. Jafari ${ }^{a}$ \\ and Ahmed Esmail Shalan (iD *bc
}

Co-MOF-based zeolitic imidazolate frameworks (ZIF-67) with various morphologies were prepared via an innovative way under distinct reaction conditions. By changing the reaction conditions, including the cobalt source, solvent, time, temperature, and linking agent to the cobalt ions, the morphological evolution of CoMOF-based ZIF-67 was investigated. The Co-MOF-based ZIF-67 was applied as an adsorbent fiber in the solid-phase microextraction (SPME) technique for extracting a herbicide, namely molinate (as a test compound), in aqueous samples. For recognizing the molinate molecules, drift tube ion mobility spectrometry (IMS) was employed as a sensitive, rapid, and simple detection technique. Two essential parameters, namely extraction temperature and extraction time, influenced the extraction efficiency, and these parameters were also analyzed and optimized. The linear dynamic range (LDR) and the determination coefficient were found to be $0.5-20.0 \mu \mathrm{g} \mathrm{L}^{-1}$ and 0.9990 , respectively. In this regard, the limit of quantification (LOQ) and the detection limit (LOD) were calculated and found to be $0.5 \mu \mathrm{g} \mathrm{L}^{-1}$ and $0.15 \mu \mathrm{g} \mathrm{L}^{-1}$, respectively. Finally, the effect of the adsorbent with different morphologies on the extraction efficiency was compared.

\section{Introduction}

One of the critical worldwide issues that humans struggle with is pesticide contamination. ${ }^{1}$ Quantity and exposure are the two main factors that indicate toxic effects on human health. Pesticides are environmental contaminants that are detected in rivers, surface waters, or soils. ${ }^{\mathbf{1}, 2}$ Molinate is a thiocarbamate herbicide extensively applied worldwide to protect weeds in rice crops. ${ }^{3,4}$ This herbicide is stable at atmospheric pressure as well as environmental temperature and is a liquid with a pungent odor, and is colorless and transparent. The heat decomposition of this compound produces toxic fumes that contain sulphur, oxygen, and nitrogen. ${ }^{5}$

Furthermore, ion mobility spectrometry (IMS) technique was introduced as a recognizing system. ${ }^{6}$ The IMS pathway depends on the movement of the ions in the constant electric field. The

${ }^{a}$ Department of Chemistry, Isfahan University of Technology, Isfahan, 84156-83111, Iran.E-mail: davar@cc.iut.ac.ir

${ }^{b}$ BCMaterials, Basque Center for Materials, Applications and Nanostructures, Martina Casiano, UPV/EHU Science Park, Barrio Sarriena s/n, Leioa 48940, Spain. E-mail: a. shalan133@gmail.com; ahmed.shalan@bcmaterials.net

${ }^{c}$ Central Metallurgical Research and Development Institute (CMRDI), P.O. Box 87, Helwan, Cairo 11421, Egypt

$\dagger$ Electronic supplementary information (ESI) available. See DOI: 10.1039/d0ra09298c gaseous compounds are ionized and then introduced with an electric shutter into a drift tube. The ionized compounds are moved to the detector in the drift tube depending on the mass, charge, and shape (intrinsic mobility) of the compound. Consequently, the IMS technique could be used for recognizing different blends, including toxic compounds (herbicides, pesticides, and insecticides), warfare agents, and abuse and clinical drugs. ${ }^{7}$

Metal-organic frameworks (MOFs), a class of porous materials, are essential for numerous scientific studies, ${ }^{8-10}$ such as catalysts, gas absorption, drug delivery, separation, electronic devices, and sensors due to their essential features, including large surface area, tunable organic ligands, high crystallization, large pore volume, and adjustable pore size. ${ }^{11-13}$ Zeolitic imidazolate frameworks (ZIFs), as a specific and new category of metal-organic frameworks, consist of metal ions and imidazolate linking agents having intrinsic porosity as well as extraordinary chemical and thermal stability. ${ }^{\mathbf{1 4 - 1 7}}$ ZIF materials are obtained via a solvothermal method, where ZIFs are prepared from organic solvents. ${ }^{18,19}$ However, organic solvents are often toxic, expensive, flammable, not environment-friendly, and not cost-effective. ${ }^{19-21}$ Accordingly, the production of ZIFs through a green method and low-cost is accordingly desired. ${ }^{22,23}$ The applications of ZIF crystals are highly influenced by the different morphology and size of the as-prepared samples. ${ }^{23-25}$ 
Numerous parameters such as temperature, duration, concentration, solvent, molar ratio of reactants, and deprotonating agents can affect the morphology and size of the ZIF crystals. $^{26-28}$

In the present study, we have reported various morphologies with a simple pathway for the preparation of Co-MOF-based ZIF-67 nanostructures. Then, to investigate the application of the introduced method, the solid-phase microextraction (SPME) method was applied for extracting the molinate herbicide, as a test compound, in aqueous samples. For recognizing the molinate molecules, ion mobility spectrometry equipped with a corona discharge ionization source was applied. Incidentally, some useful parameters on the extraction efficiency were checked and optimized. Furthermore, we have shown that the use of methanol as a solvent brings the highest extraction efficiency compared to using a mixture of water with methanol or water as a solvent.

\section{Experimental section}

\subsection{Materials}

All chemicals in this project were applied without further purification. $\mathrm{CoCl}_{2} \cdot 2 \mathrm{H}_{2} \mathrm{O}, \mathrm{Co}\left(\mathrm{SO}_{4}\right) \cdot 4 \mathrm{H}_{2} \mathrm{O}, \mathrm{Co}\left(\mathrm{NO}_{3}\right)_{2} \cdot 6 \mathrm{H}_{2} \mathrm{O}, 2$ methylimidazole, absolute ethanol, and anhydrous methanol were purchased from Merck company. Herbicide molinate (98\% purity) was purchased from Kavosh Kimia Kerman Co., Iran.

\subsection{Synthesis of Co-MOF-based ZIF-67}

Co-MOF-based ZIF-67 samples with various morphologies were synthesized, as stated by the research conducted by a different method. ${ }^{28}$ In brief, $328 \mathrm{mg}$ of 2-methylimidazole (as a linking agent) and $291.05 \mathrm{mg}$ cobalt(II) nitrate hexahydrate (as a source of $\mathrm{Co}^{2+}$ ) with a stoichiometric ratio of $1: 4$ were dissolved in
$20 \mathrm{~mL}$ and $10 \mathrm{~mL}$ of a mixture of methanol-water and ethanolwater, with the different molar ratio, respectively. Besides, solutions were mixed and stirred at room temperature for $30 \mathrm{~min}$. Then, the resulting purple solution was transferred into a $40 \mathrm{~mL}$ Teflon-lined autoclave and heated in a constant temperature drying oven for $30 \mathrm{~min}$ at $100{ }^{\circ} \mathrm{C}$. The obtained solution was kept at room temperature for $3 \mathrm{~h}$ without stirring. After centrifugation of the resulting solution, the resulting precipitates were collected, washed two times with ethanol and deionized water to remove the potential contaminants, and were dried overnight in an oven at $80{ }^{\circ} \mathrm{C}$. In general, in this study, the effect of distinct reaction parameters, including solvent, reaction temperature, reaction time, cobalt source, and the cobalt to the imidazole molar proportions, was investigated (Table 1).

\subsection{Characterization of the obtained samples}

Fourier transform infrared (FTIR) spectra were obtained with a $\mathrm{KBr}$ pellet at a resolution of $4 \mathrm{~cm}^{-1}$ using a 680-PLUS FT-IR spectrometer (JASCO, Japan) in the range of $400-4000 \mathrm{~cm}^{-1}$. In addition, a JASCO V-750 UV-Spectrophotometer in the range of 400-800 $\mathrm{nm}$ was used to investigate the electronic transmissions. Besides, RF-5301pc was applied to measure the photoluminescence spectra of Co-MOFs-based ZIF-67 samples at an excitation wavelength of $490 \mathrm{~nm}$. X-ray diffraction (XRD) patterns were recorded on an X-Pert Pro-MPD Philips with $\mathrm{Cu} \mathrm{K}_{\alpha}$ radiation $(\lambda=0.15406 \mathrm{~nm})$ at a voltage of $40 \mathrm{kV}$ in the range of $2 \theta=5-50^{\circ}$ with the current of $30 \mathrm{~mA}$. Furthermore, field emission scanning electron microscopy (FE-SEM, FEI model, made in the USA) was used to characterize the morphology of the samples. The BET analysis was described using a BELSORPmini II apparatus made by MicrotracBEL company (nitrogen adsorption-desorption at $273 \mathrm{k}$ ). A Pyris1 device was utilized to

Table 1 Summary of the sample code table of the as-synthesized Co-MOF-based ZIF-67 nanostructures under different reaction parameters

\begin{tabular}{|c|c|c|c|c|c|}
\hline Sample code & Time (h) & Temperature $\left({ }^{\circ} \mathrm{C}\right)$ & Solvent & Cobalt source & $\begin{array}{l}\text { 2-Methylimidazolate } \\
(\mathrm{Hmim}) / \mathrm{Co}^{2+} \text { molar ratio }\end{array}$ \\
\hline $\mathrm{HC}_{1}$ & 12 & 25 & Methanol & $\mathrm{CoNO}_{3} \cdot 6 \mathrm{H}_{2} \mathrm{O}$ & $1.5 / 1$ \\
\hline $\mathrm{HC}_{2}$ & 12 & 25 & Methanol & $\mathrm{CoNO}_{3} \cdot 6 \mathrm{H}_{2} \mathrm{O}$ & $2 / 1$ \\
\hline $\mathrm{HC}_{3}$ & 12 & 25 & Methanol & $\mathrm{CoNO}_{3} \cdot 6 \mathrm{H}_{2} \mathrm{O}$ & $6 / 1$ \\
\hline $\mathrm{HC}_{4}$ & 12 & 25 & Methanol & $\mathrm{CoNO}_{3} \cdot 6 \mathrm{H}_{2} \mathrm{O}$ & $16 / 1$ \\
\hline $\mathrm{SO}_{1}$ & 12 & 25 & Methanol (M) & $\mathrm{CoNO}_{3} \cdot 6 \mathrm{H}_{2} \mathrm{O}$ & $4 / 1$ \\
\hline $\mathrm{SO}_{2}$ & 12 & 25 & Ethanol (E) & $\mathrm{CoNO}_{3} \cdot 6 \mathrm{H}_{2} \mathrm{O}$ & $4 / 1$ \\
\hline $\mathrm{SO}_{3}$ & 12 & 25 & Water (W) & $\mathrm{CoNO}_{3} \cdot 6 \mathrm{H}_{2} \mathrm{O}$ & $4 / 1$ \\
\hline $\mathrm{SO}_{4}$ & 12 & 25 & $\mathrm{~W}-\mathrm{M}(1-2)$ & $\mathrm{CoNO}_{3} \cdot 6 \mathrm{H}_{2} \mathrm{O}$ & $4 / 1$ \\
\hline $\mathrm{SO}_{5}$ & 12 & 25 & $\mathrm{~W}-\mathrm{E}(1-2)$ & $\mathrm{CoNO}_{3} \cdot 6 \mathrm{H}_{2} \mathrm{O}$ & $4 / 1$ \\
\hline $\mathrm{CS}_{1}$ & 12 & 25 & Methanol & $\mathrm{CoNO}_{3} \cdot 6 \mathrm{H}_{2} \mathrm{O}$ & $4 / 1$ \\
\hline $\mathrm{CS}_{2}$ & 12 & 25 & Methanol & $\mathrm{CoCl}_{2} \cdot 2 \mathrm{H}_{2} \mathrm{O}$ & $4 / 1$ \\
\hline $\mathrm{CS}_{3}$ & 12 & 25 & Methanol & $\mathrm{Co}\left(\mathrm{SO}_{4}\right) \cdot 4 \mathrm{H}_{2} \mathrm{O}$ & $4 / 1$ \\
\hline $\mathrm{Te}_{1}$ & 12 & 100 & $\mathrm{~W}-\mathrm{M}(1-2)$ & $\mathrm{CoNO}_{3} \cdot 6 \mathrm{H}_{2} \mathrm{O}$ & $4 / 1$ \\
\hline $\mathrm{Te}_{2}$ & 12 & 100 & Water & $\mathrm{CoNO}_{3} \cdot 6 \mathrm{H}_{2} \mathrm{O}$ & $16 / 1$ \\
\hline $\mathrm{Te}_{3}$ & 12 & 100 & Methanol & $\mathrm{CoNO}_{3} \cdot 6 \mathrm{H}_{2} \mathrm{O}$ & $16 / 1$ \\
\hline $\mathrm{Ti}_{1}$ & 0.5 & 25 & Methanol & $\mathrm{CoNO}_{3} \cdot 6 \mathrm{H}_{2} \mathrm{O}$ & $4 / 1$ \\
\hline $\mathrm{Ti}_{2}$ & 6 & 25 & Methanol & $\mathrm{CoNO}_{3} \cdot 6 \mathrm{H}_{2} \mathrm{O}$ & $4 / 1$ \\
\hline $\mathrm{Ti}_{3}$ & 12 & 25 & Methanol & $\mathrm{CoNO}_{3} \cdot 6 \mathrm{H}_{2} \mathrm{O}$ & $4 / 1$ \\
\hline $\mathrm{Ti}_{4}$ & 48 & 25 & Methanol & $\mathrm{CoNO}_{3} \cdot 6 \mathrm{H}_{2} \mathrm{O}$ & $4 / 1$ \\
\hline
\end{tabular}


evaluate the thermal stability of Co-MOF-based ZIF-67 samples via thermometric analysis (TGA) under a nitrogen atmosphere at $10^{\circ} \mathrm{min}^{-1}$. Corona discharge ionization-ion mobility spectrometry (CD-IMS) as a detection technique was considered and assembled at Teif Azmon Espadana Co, Isfahan, Iran. Furthermore, the instrumental conditions of the CD-IMS are shown in Table S1, in the ESI. $\dagger$

\subsection{Preparation of the solid-phase microextraction (SPME)} fiber

The wire was immersed in methanol to remove the pollutants from the Ni-Cr wire through the SPME method (SPME fiber). Also, the silicone glue $(10 \% \mathrm{w} / \mathrm{v})$ was prepared in the toluene solvent, and the Ni-Cr wire was placed in this solution for $1 \mathrm{~min}$. Then, the wire was withdrawn from the glue solution and introduced to the ZIF-67 adsorbent for $1 \mathrm{~min}$. Finally, the Ni-Cr wire coated by the ZIF-67 adsorbent was placed at the temperature of $220^{\circ} \mathrm{C}$ for $20 \mathrm{mi}$ to remove the toluene solvent and the pollutants.

\subsection{Evaluation of Co-MOF-based ZIF-67 performance as an adsorbent for the SPME method}

Fig. 1 shows the schematic of the SPME procedure, along with an analysis of molinate by CD-IMS. Furthermore, $10 \mathrm{~mL}$ of the molinate aqueous solution was placed into a $15 \mathrm{~mL}$ glass vial as an extraction cell and placed on a stirrer with the temperature set at $10{ }^{\circ} \mathrm{C}$. The proposed adsorbent-coated SPME wire was positioned into the molinate solution for $30 \mathrm{~min}$ at a stirring rate of $400 \mathrm{rpm}$. After achieving the equilibrium time between the adsorbent and sample solution, the ZIF-67 SPME wire was withdrawn and introduced to the CD-IMS injection port $\left(220^{\circ} \mathrm{C}\right)$ at once.

\section{Results and discussion}

Fig. 2a and b shows the FTIR spectrum of Co-MOF-based ZIF-67 with different solvents and Co-MOF-based ZIF-67 with several $\mathrm{Hmim} / \mathrm{Co}^{2+}$ molar ratios, respectively. Most of the obtained bands in the Co-MOF-based ZIF-67 are related to the vibration of the imidazole ring and can be interpreted based on the origin of these bands. In the spectrum of Co-MOF-based ZIF-67, the bands at about $3400 \mathrm{~cm}^{-1}$ are related to the $\mathrm{O}-\mathrm{H}$ stretching vibration of the hydroxyl groups. ${ }^{28,29}$ The bands at about 600$1500 \mathrm{~cm}^{-1}$ are attributed to the bending and stretching modes of the imidazole ring. ${ }^{30,31}$ Besides, the bands at 2400 and 3000 $\mathrm{cm}^{-1}$ in the spectrum of Hmim are assigned to the vibration bending of the $\mathrm{N}-\mathrm{H}$ functional group. ${ }^{32}$ The bands at about 1570 and $1618 \mathrm{~cm}^{-1}$ in the spectrum of Co-MOF-based ZIF-67 and Hmim are attributed to the $\mathrm{C}=\mathrm{N}$ stretching vibration. ${ }^{23,33,34}$ Besides, the band observed at $1420 \mathrm{~cm}^{-1}$ in the spectrum of CoMOF-based ZIF-67 and Hmim is related to the $\mathrm{C}=\mathrm{C}$ bond in the imidazole ring. ${ }^{23,35}$ Furthermore, the band observed at about $429 \mathrm{~cm}^{-1}$ in the spectrum of Co-MOF-based ZIF-67 is attributed to the Co-N bonds. ${ }^{36,37}$ In the spectrum of Co-MOFs-based ZIF67 , the presence of metal-nitrogen vibrations, absence of the $\mathrm{NH}$ bond, and $\mathrm{C}=\mathrm{N}$ shifted peak to the lower wavenumbers represent considerable effects of the metal ions on the binding agent, confirming the formation of imidazole zeolites $(-\mathrm{NH}$ group of Hmim). ${ }^{36-38}$

The UV-Vis spectra of the ZIF-67 prepared using different solvents are given in Fig. S1, in the ESI section. $\dagger$ The interactions between the solvent and the compound cause different maximum wavelengths that affect the electron density on the
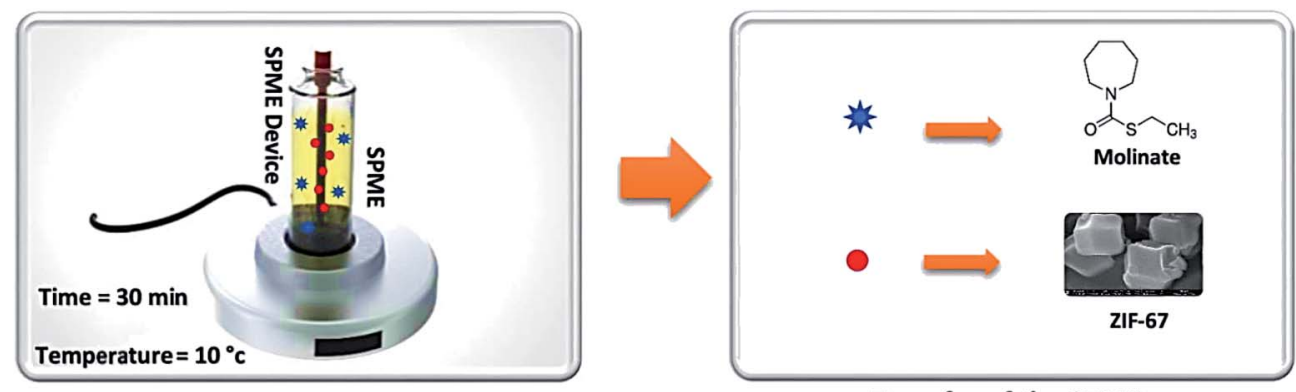

Transfer of the SPME
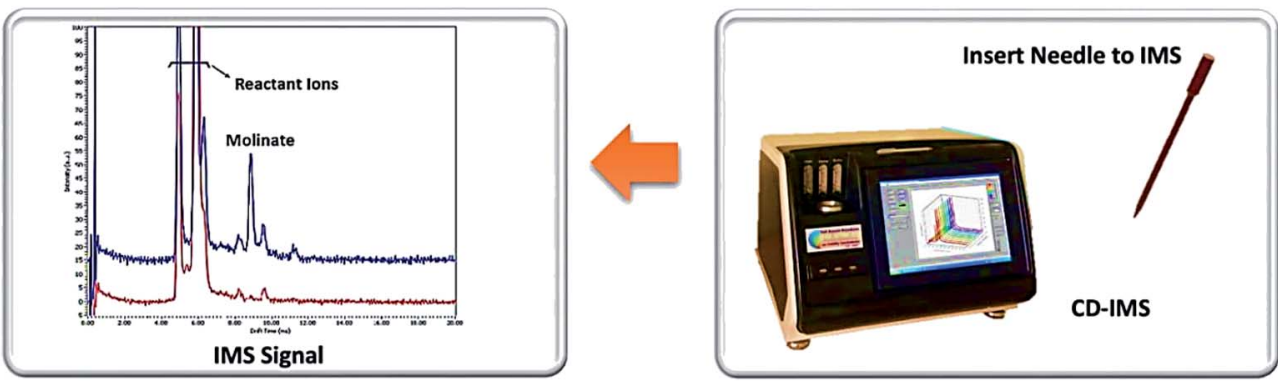

Fig. 1 The schematic of the SPME procedure along with the analysis of the molinate by the CD-IMS apparatus. 
(a)

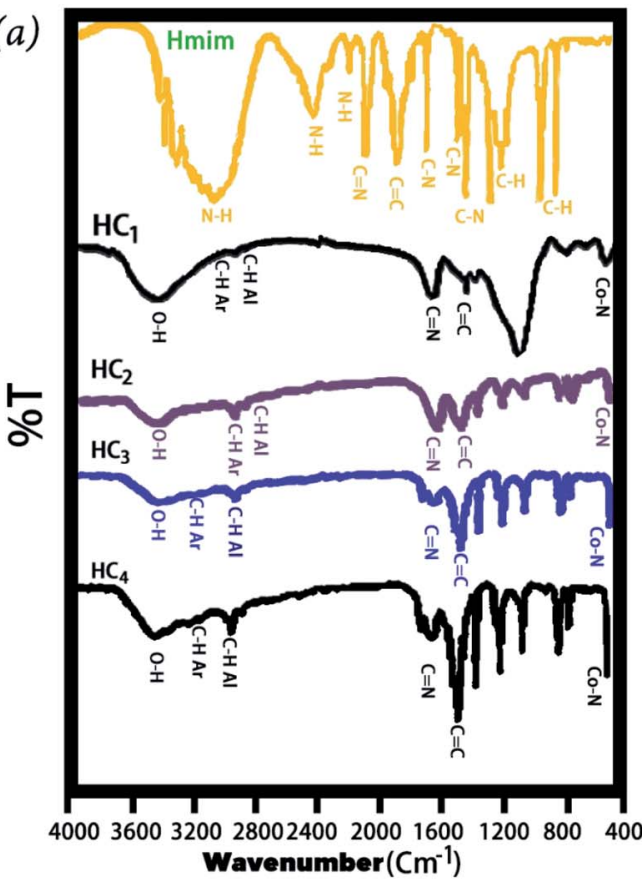

(b)

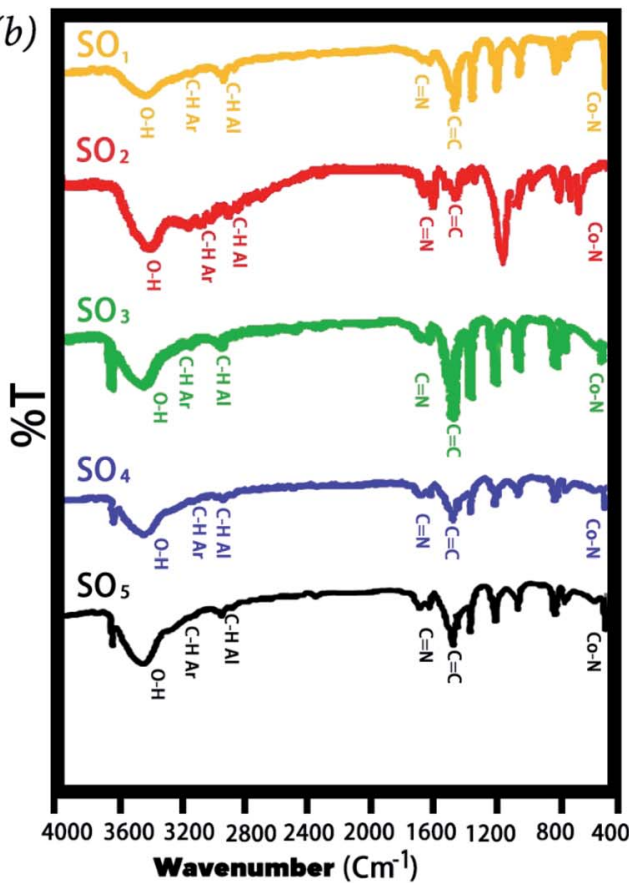

Fig. 2 FT-IR spectra of Co-MOF-based ZIF-67, prepared with (a) different Hmim/Co ${ }^{2+}$ molar proportions, Hmim (2-methylimidazolate), $\mathrm{HC}_{1}(1.5), \mathrm{HC}_{2}(2), \mathrm{HC}_{3}(6)$, and $\mathrm{HC}_{4}(16)$ (b) different solvents, $\mathrm{SO}_{1}$ (methanol), $\mathrm{SO}_{2}$ (ethanol), $\mathrm{SO}_{3}$ (water), $\mathrm{SO}_{4}$ (methanol-water), $\mathrm{SO}_{5}$ (ethanolwater).

surface, which is related to the ligand-to-metal charge-transfer (LMCT) characteristics. It demonstrates that the Co-MOFsbased ZIF-67 samples have a blue to red light reaping ability. ${ }^{34,38}$ From Fig. S1, ESI, $\dagger$ we can notice that the lowest absorbance and accordingly the highest transmission was obtained for the sample when water was used as a solvent due to its longer wavelength and lower energy compared to other samples..$^{38}$ The absorbance peaks appeared at 594, 586, 618, and $514 \mathrm{~nm}$ for methanol, ethanol, water, and methanol-water, respectively. Furthermore, Fig. S2, ESI $\uparrow$ shows the PL spectra of the Co-MOF-based ZIF-67 synthesized with different solvents excited by a laser source at a wavelength of $490 \mathrm{~nm} \cdot{ }^{39}$ The PL spectra show emitted light in the range of 540 to $630 \mathrm{~nm}$. Interactions between the solvent and the compound cause different emitted rays in the light range of blue to green. It is observed that when a mixture of ethanol-water is used as a solvent, lower electronic transmission was obtained due to its lower wavelength and more energy compared to other samples.

The XRD pattern of Co-MOF-based ZIF-67 prepared by varying the reaction parameters, including the different solvent and different $\mathrm{Hmim} / \mathrm{Co}^{2+}$ molar proportions, are shown in Fig. 3. The high intensity of the reflections and narrowness as well as the sharpness of these peaks show the high crystallinity percentage of the prepared Co-MOF-based ZIF-67. On the one hand, it is observed that the different $\mathrm{Hmim} / \mathrm{Co}^{2+}$ molar proportions of the organic ligand to metal ions, $\mathrm{HC}_{1}(1.5)$, $\mathrm{HC}_{2}(2), \mathrm{HC}_{3}(6)$, and $\mathrm{HC}_{4}(16)$, play an important role in the formation of Co-MOF-based ZIF-67 crystal structures (Fig. 3a). When the proportion of the ligand to the metal ions is low (around 1.5), the as-prepared sample is found to be $\left[\mathrm{Co}(\mathrm{OH})_{2}\right]$ with a layered structure. ${ }^{40}$ By reaching the appropriate molar proportion, pure phase crystals of Co-MOF-based ZIF-67 are formed. On the other hand, for the different solvent $\mathrm{SO}_{1}$ (methanol), $\mathrm{SO}_{2}$ (ethanol), $\mathrm{SO}_{3}$ (water), $\mathrm{SO}_{4}$ (methanol-water), and $\mathrm{SO}_{5}$ (ethanol-water), we can notice that the XRD pattern of $\mathrm{SO}_{1}$ and $\mathrm{SO}_{2}$ samples display a different crystal structure as compared to that of other samples. $\mathrm{SO}_{3}$ and $\mathrm{SO}_{4}$ samples have almost similar XRD patterns matching with prior standard records of Co-MOF-based ZIF-67 materials with a sodalite topology (Fig. 3b). . $^{34,41}$

Fig. 4 displays the FE-SEM images of Co-MOF-based ZIF-67 prepared using different solvents: $\mathrm{SO}_{1}$ (methanol), $\mathrm{SO}_{2}$ (ethanol), $\mathrm{SO}_{3}$ (water), $\mathrm{SO}_{4}$ (methanol-water), and $\mathrm{SO}_{5}$ (ethanolwater). Besides, the particle size distribution of Co-MOF-based ZIF-67 prepared using different solvents, including $\mathrm{SO}_{1}$ (methanol) and $\mathrm{SO}_{2}$ (ethanol) as examples, is given in Fig. S3, ESI. $\dagger$ Morphology variation is observed by changing the ratio and the type of solvent. ${ }^{34}$ When methanol is applied as a solvent $\left(\mathrm{SO}_{1}\right)$, relatively uniform particles and rhombic dodecahedron morphology with an average size of $344 \mathrm{~nm}$ are observed, as shown in Fig. 4a. When ethanol is used as a solvent $\left(\mathrm{SO}_{2}\right)$, the strand-like morphology with a size of $249 \mathrm{~nm}$ is observed (Fig. 4b). By using water as a solvent $\left(\mathrm{SO}_{3}\right)$, the leaf-like morphology in two dimensions with larger dimensions than the previous two cases, and a smooth surface is observed (Fig. 4c). In the case of a mixture of water and methanol, the agglomerated hexagonal morphology and pita-like shape are observed (Fig. 4d). The morphology of samples with water and ethanol as solvents $\left(\mathrm{SO}_{5}\right)$ is observed to be similar to the previous one $\left(\mathrm{SO}_{4}\right)$ with a smaller size, as shown in Fig. 4e. 
(a)

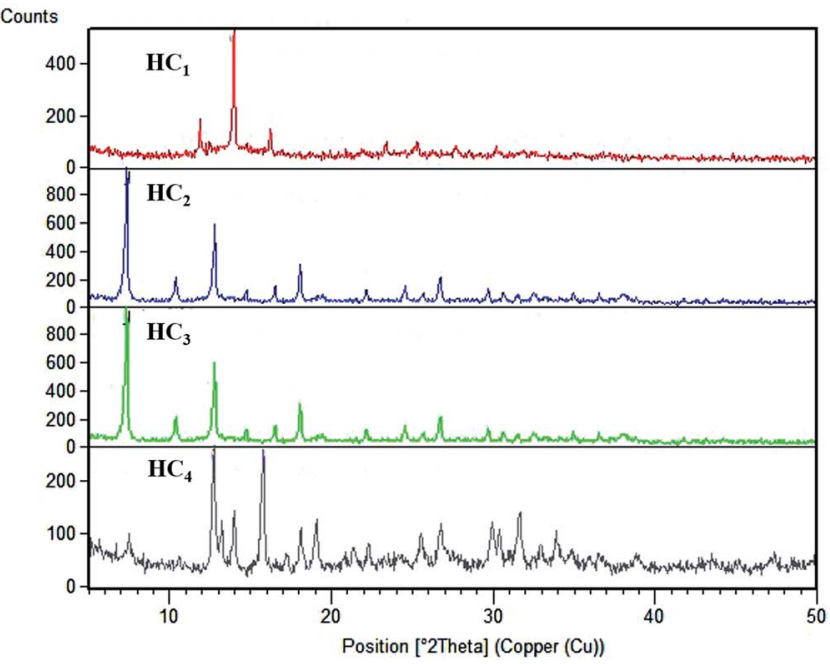

(b)

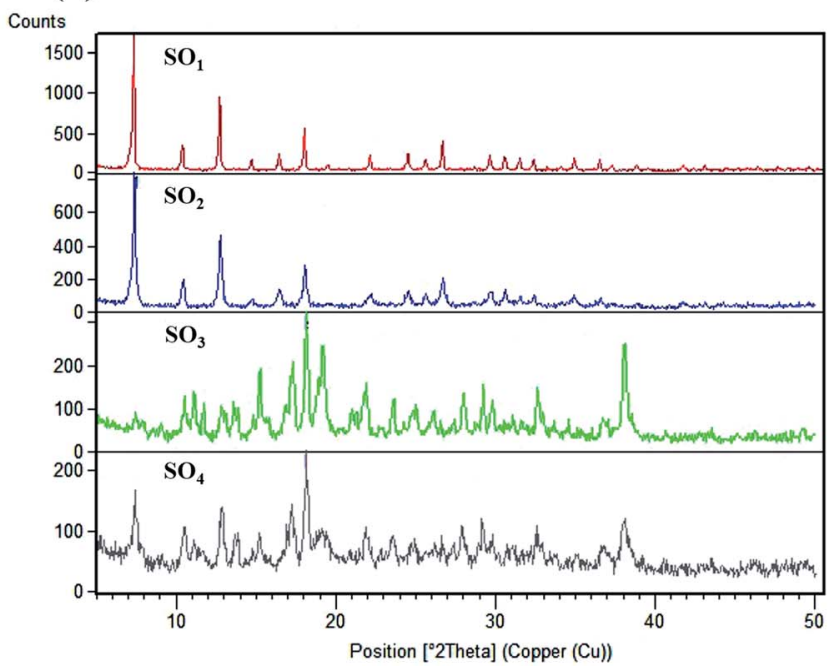

Fig. 3 XRD of Co-MOFs based ZIF-67 prepared with (a) different $\mathrm{Hmim} / \mathrm{Co}^{2+}$ molar ratios, $\mathrm{HC}_{1}(1.5), \mathrm{HC}_{2}(2), \mathrm{HC}_{3}(6)$, and $\mathrm{HC}_{4}(16)(\mathrm{b})$ different solvents, $\mathrm{SO}_{1}$ (methanol), $\mathrm{SO}_{2}$ (ethanol), $\mathrm{SO}_{3}$ (water), and $\mathrm{SO}_{4}$ (methanol-water).
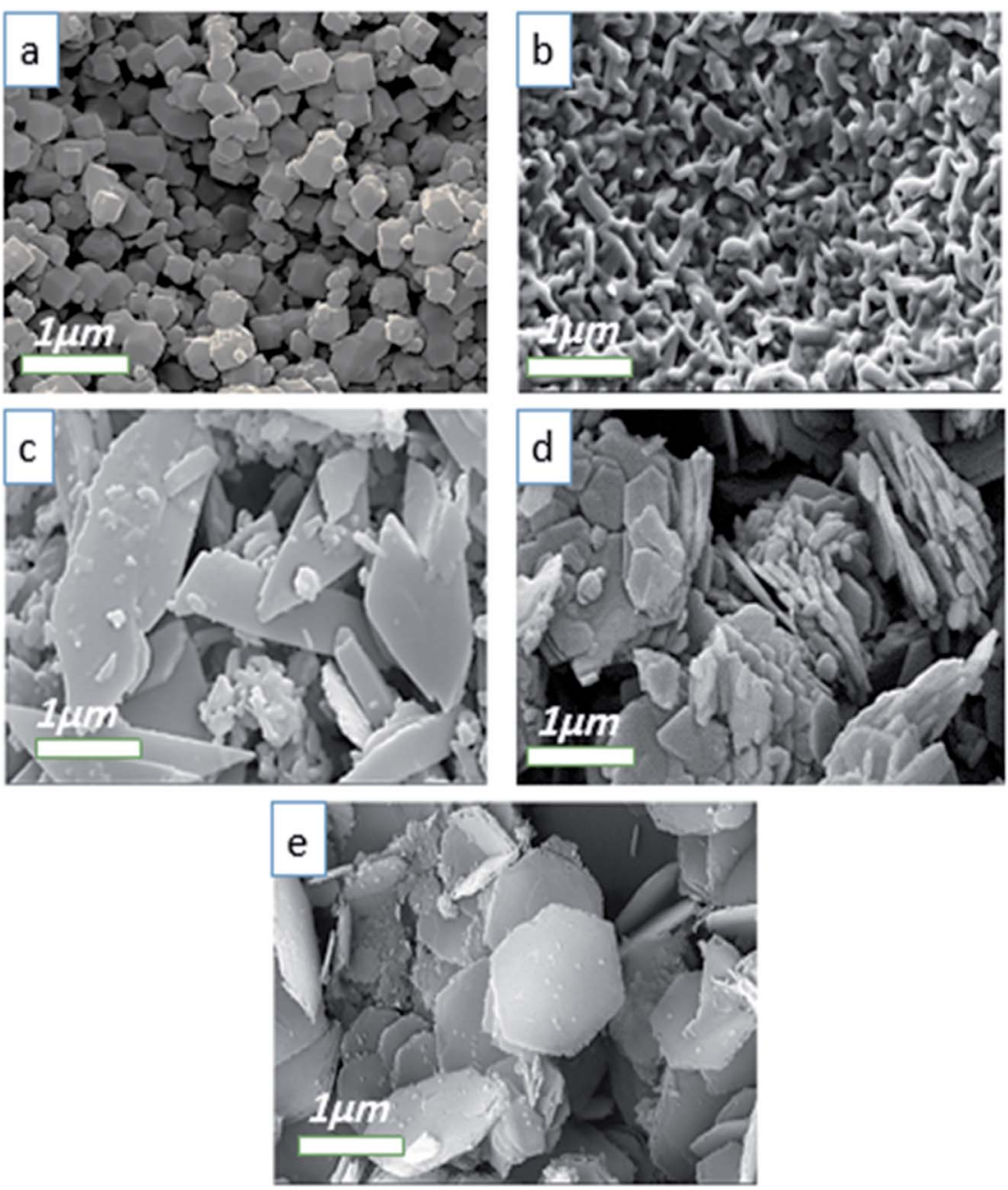

Fig. 4 FE-SEM images of Co-MOF-based ZIF-67 prepared with different solvents (a) methanol, $\mathrm{SO}_{1}$ (b) ethanol, $\mathrm{SO}_{2}$ (c) water, $\mathrm{SO}_{3}$ (d) methanolwater, $\mathrm{SO}_{1}$, and (e) ethanol-water, $\mathrm{SO}_{5}$. 

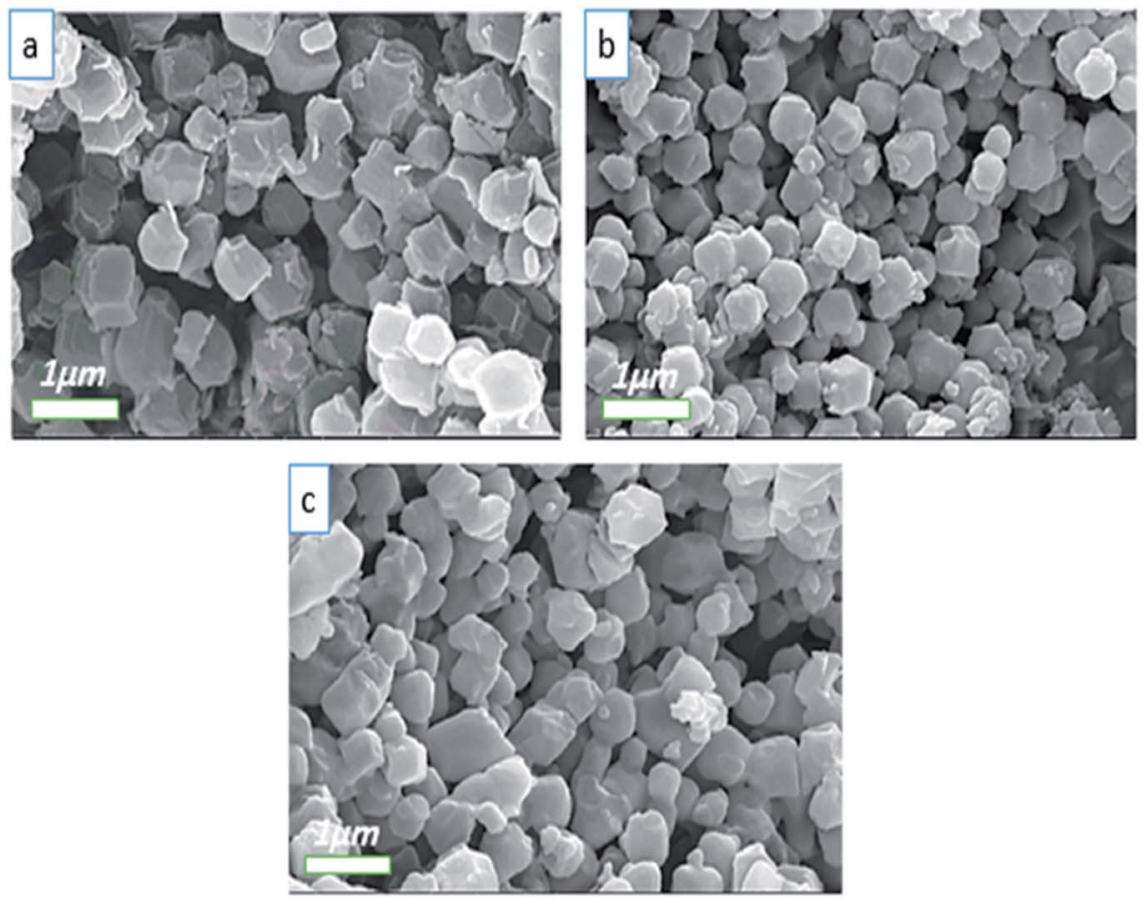

Fig. 5 FE-SEM images of Co-MOF-based ZIF-67 prepared with different cobalt sources: (a) $\mathrm{Co}\left(\mathrm{NO}_{3}\right)_{2}, \mathrm{CS}_{1}$, (b) $\mathrm{CoCl}_{2}, \mathrm{CS}_{2}$, and (c) $\mathrm{CoSO}_{4}, \mathrm{CS}_{3}$.

Besides, the particle size distribution was calculated by studying the statistical analysis of the as-prepared materials with different types of solvents via the free software Image J. ${ }^{42}$ The statistical analysis of the particles for Co-MOF-based ZIF-67 obtained with ethanol and methanol as solvents revealed an average size distribution of 250 and $350 \mathrm{~nm}$, respectively, as illustrated in Fig. S3a and b, ESI.† By using a mixture of methanol and water as a solvent, the particles tend to
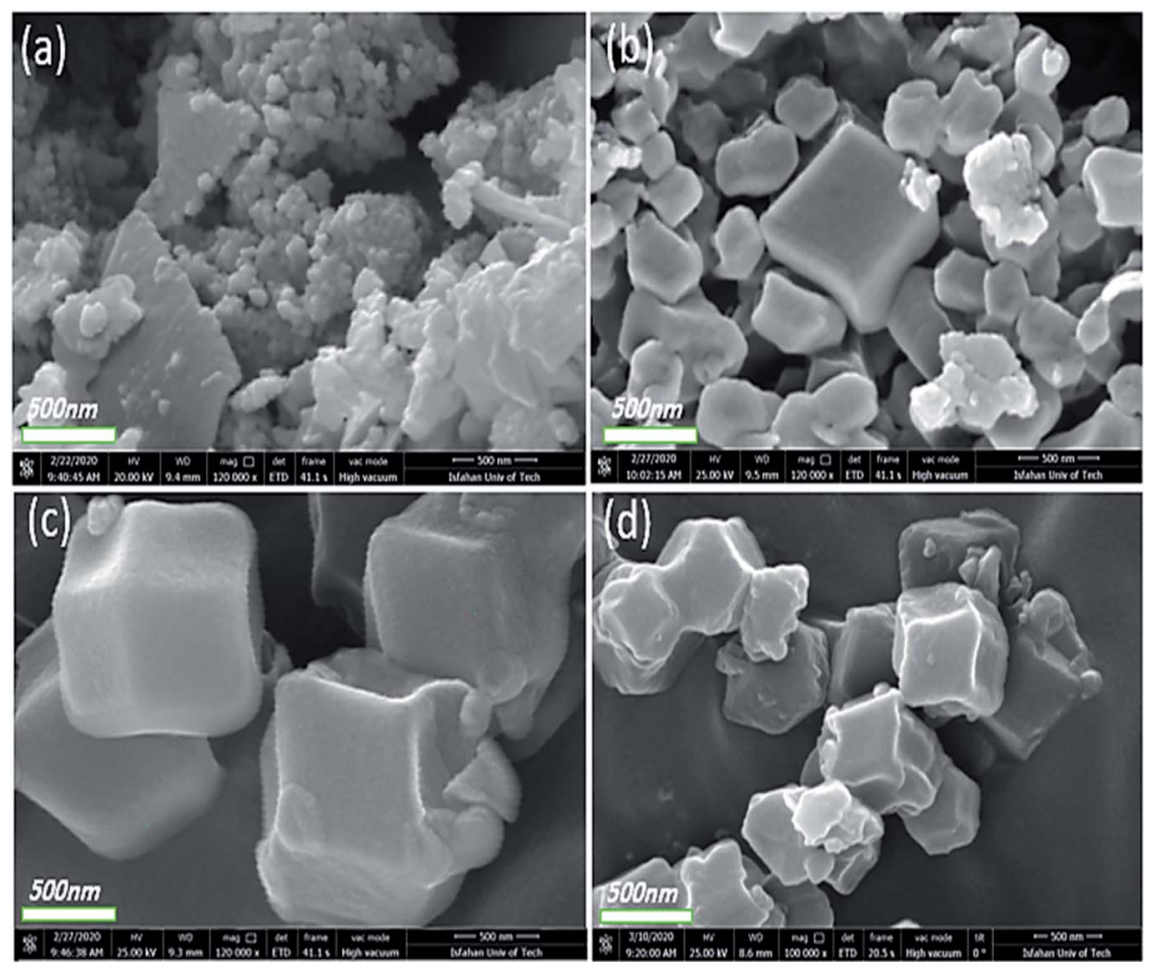

Fig. 6 FE-SEM images of Co-MOF-based ZIF-67 prepared with different $\mathrm{Hmim} / \mathrm{Co}^{2+}$ molar proportions (a) 1.5, $\mathrm{HC}_{1}$, (b) 2, $\mathrm{HC}_{2}$, (c) 6, $\mathrm{HC}_{3}$, and (d) $16, \mathrm{HC}_{4}$ 

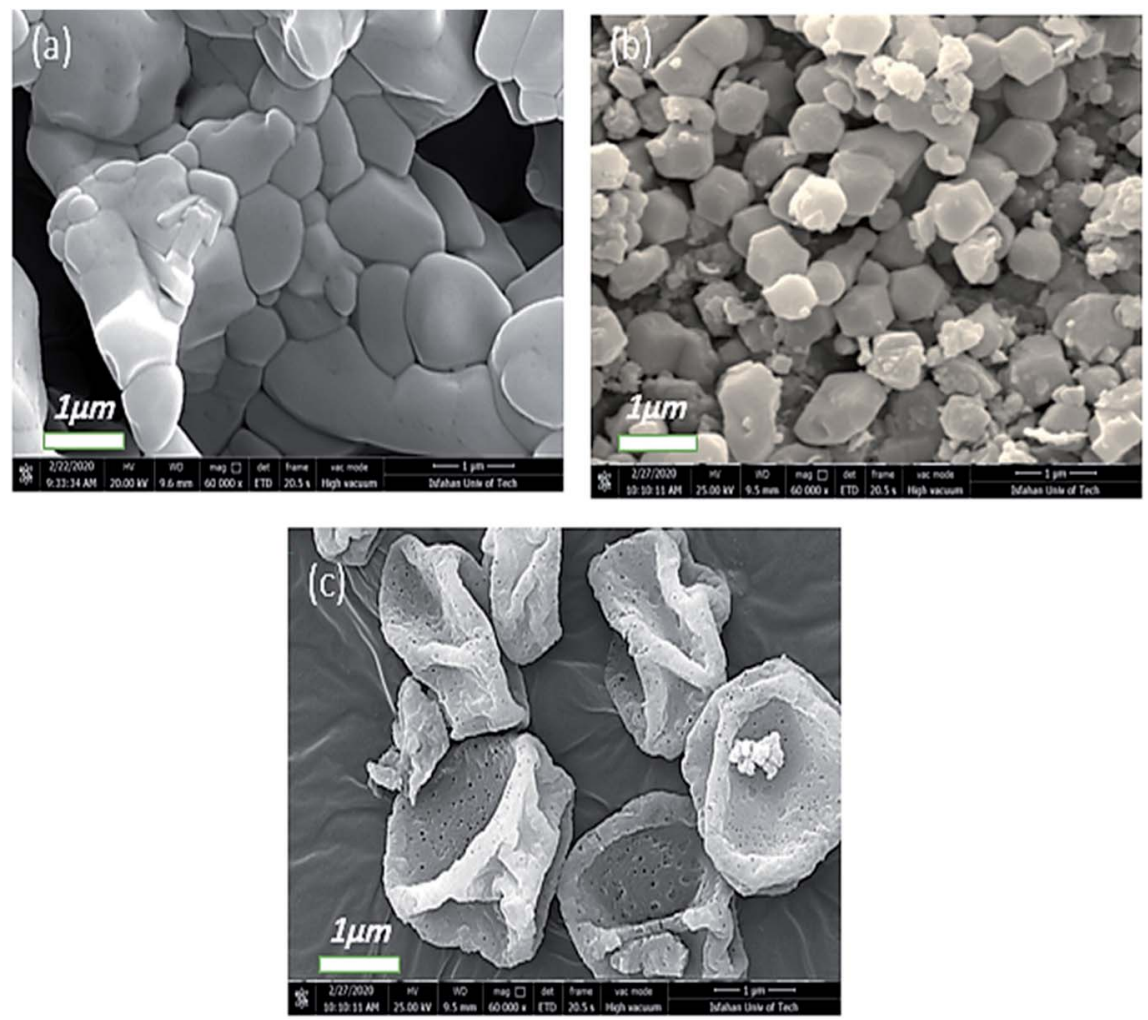

Fig. 7 FE-SEM images of Co-MOF-based ZIF-67 prepared with different reaction times (a) $30 \mathrm{~min}, \mathrm{Ti}_{1}$, (b) $6 \mathrm{~h}, \mathrm{Ti}_{2}$, and (c) $48 \mathrm{~h}, \mathrm{Ti}_{4}$.
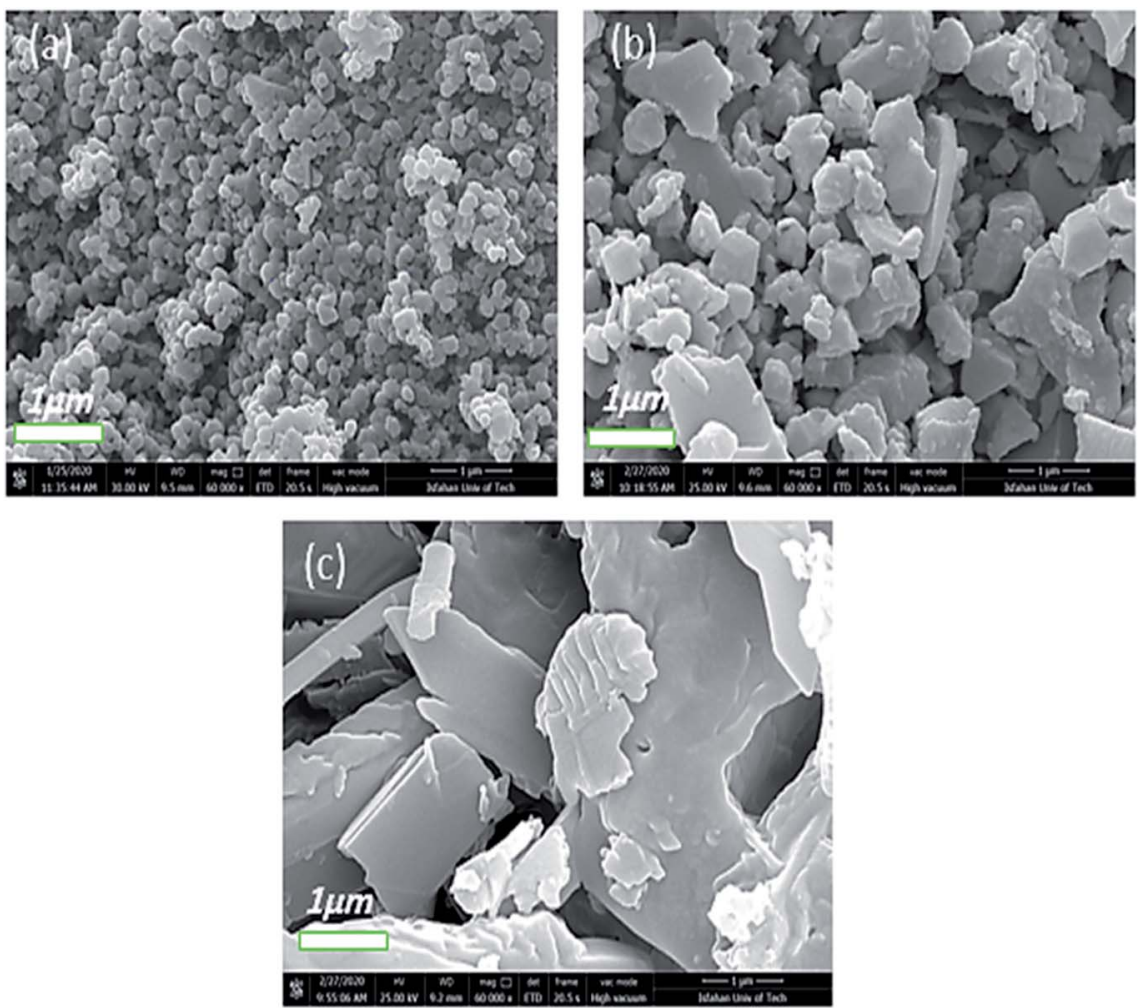

Fig. 8 FE-SEM images of Co-MOF-based ZIF-67 prepared at different temperatures indicated as (a) $\mathrm{Te}_{1}$, (b) $\mathrm{Te}_{2}$, and (c) Te 

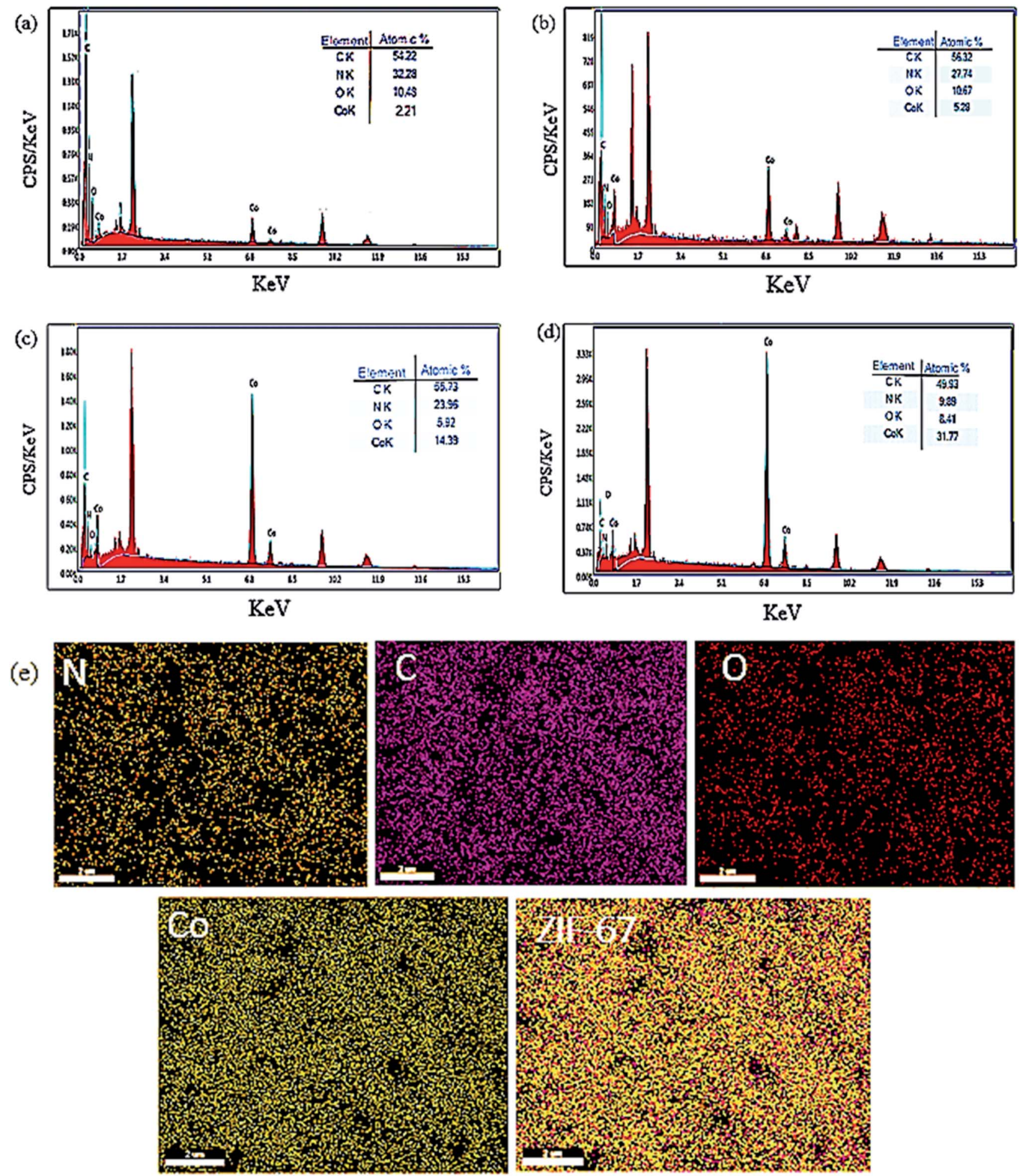

Fig. 9 EDX analysis of Co-MOF-based ZIF-67 prepared with several Hmim/Co ${ }^{2+}$ molar proportions (a) 40, (b) 16, (c) 6, (d) 2, (e) X-ray mapping of Co-MOFs-based ZIF-67 for $\mathrm{HC}_{2}$

agglomerate, which can be due to the fact that there is less nucleation and more growth, and the resulting particles have a large size. When a mixture of ethanol and water is used, the resulting particles have a distinct hexagonal sheet morphology with a thickness of less than $100 \mathrm{~nm}$.

On the other hand, by replacing the cobalt source from $\mathrm{Co}\left(\mathrm{NO}_{3}\right)_{2}$ to $\mathrm{CoSO}_{4}$ and $\mathrm{Co}(\mathrm{Cl})_{2}$, the coordination reactions 
between cobalt and imidazole probably changed. Due to the different interaction pathways between $\mathrm{Co}^{2+}$ and $\mathrm{Cl}^{-}, \mathrm{SO}_{4}{ }^{2-}$ and $\mathrm{NO}_{3}{ }^{-}$, the nucleation rate can be altered. ${ }^{43}$ As a result, when the rate of nucleation changed, we found that particles of different sizes were produced. Another factor is the amount of hydrolysis between cobalt and imidazole, which affects the size and morphology of different crystals of the produced particles. Fig. 5a-c demonstrates the FE-SEM images of Co-MOF-based ZIF-67 prepared with different cobalt sources: $\mathrm{Co}\left(\mathrm{NO}_{3}\right)_{2}$, $\mathrm{CoCl}_{2}$, and $\mathrm{CoSO}_{4}$. The obtained images of the different cobalt source samples indicate the homogeneity of the structure with a cubic like shape. Both the size as well as the morphology of the crystal structures are changed by changing the cobalt source. Furthermore, the average size of ZIF-67 nanostructures prepared with $\mathrm{Co}(\mathrm{Cl})_{2}$ as well as $\mathrm{CoSO}_{4}$ as cobalt sources, reduced from $404 \mathrm{~nm}$ to $287 \mathrm{~nm}$ (see Fig. S4, ESI $\dagger$ ).

In general, another factor that can influence the shape of ZIFs is the change in the molar proportion of the ligand to the metal ions. ${ }^{44,45}$ Fig. 6a-d displays the FE-SEM images of CoMOF-based ZIF-67 obtained with different $\mathrm{Hmim} / \mathrm{Co}^{2+}$ molar proportions of 1.5 for $\mathrm{HC}_{1}, 2$ for $\mathrm{HC}_{2}, 6$ for $\mathrm{HC}_{3}$, and 16 for $\mathrm{HC}_{4}$, respectively. Besides, by increasing this proportion, the organic ligands further restrict the bonding between metal ions and prevent their growth. When the molar proportion of imidazole to cobalt is 1.5 to 1 , Co-MOF-based ZIF-67 agglomerated particles are formed. Nonetheless, with other samples, a mixture of pseudo-cubic and star-like shapes are formed.

Consequently, the reaction time is considered another important factor that affects the preparation and morphology of Co-MOF-based ZIF-67, as shown in Fig. 7. According to the SEM images in Fig. 7, when the reaction time increases, the particle size increases, which can be attributed to the Ostwald growth behaviour. ${ }^{46}$ When the reaction time is $30 \mathrm{~min}$ (Fig. 7a), CoMOF-based ZIF-67 particles are agglomerated, but in $6 \mathrm{~h}\left(\mathrm{Ti}_{2}\right.$ sample), separated hexagonal shape particles with a diameter of $\sim 1 \mu \mathrm{m}$ were obtained (Fig. 7b). Upon increasing the reaction time to 48 h (Fig. 7c), sponge-like hollow, pseudo-spheres were achieved.

Another factor that influenced the properties as well as the morphology of the as-prepared Co-MOF-based ZIF-67 crystals is the reaction temperature. Fig. 8 displays the FE-SEM images of Co-MOF-based ZIF-67 prepared at different reaction temperatures. Former studies confirm the phenomenon, which indicates that the size of the Co-MOF-based ZIF-67 crystals under non-temperature conditions (room temperature) is larger than the crystals under different temperature conditions. ${ }^{41}$ In this study, it is concluded that the reason beyond that phenomenon is the reactants, which are completely dissolved under thermal conditions; therefore, a large number of nuclei were formed and lead to small crystals. Alternatively, nuclei grow relatively slowly at room temperature, leading to large crystals. Therefore, under temperature conditions, the size and morphology of the CoMOF-based ZIF-67 crystals tend to be more uniform and regular in structure. Besides, the average size of the Co-MOFbased ZIF-67 nanostructures prepared at room temperature $\left(25^{\circ} \mathrm{C}\right)$ was increased from $146 \mathrm{~nm}$ to $316 \mathrm{~nm}$ rather than those synthesized under the temperature condition of $100{ }^{\circ} \mathrm{C}$ (see Fig. S5, ESI $\dagger$ ).

To gain more information about the composition of the asprepared materials, the EDX and EDS mapping of the CoMOF-based ZIF-67 undergoing several $\mathrm{Hmim} / \mathrm{Co}^{2+}$ molar proportions (Fig. 9) were obtained. It is known that the EDX analysis has an error in detecting elements with a low atomic number. ${ }^{41}$ However, overall, this method confirmed the presence of $\mathrm{Co}$ and $\mathrm{O}, \mathrm{N}, \mathrm{C}$ with the desired $\mathrm{Hmim} / \mathrm{Co}^{2+}$ molar ratios in the as-prepared sample (Fig. 9a-d). The presence of existing elements as well as their uniform distribution in the $\mathrm{HC}_{2}$ sample has been confirmed using an X-ray mapping analysis (Fig. 9e). The information gained from the X-ray mapping analysis can affirm the microstructure and properties of the asprepared materials through the images of the elemental distribution in a sample. Through this technique, we can know

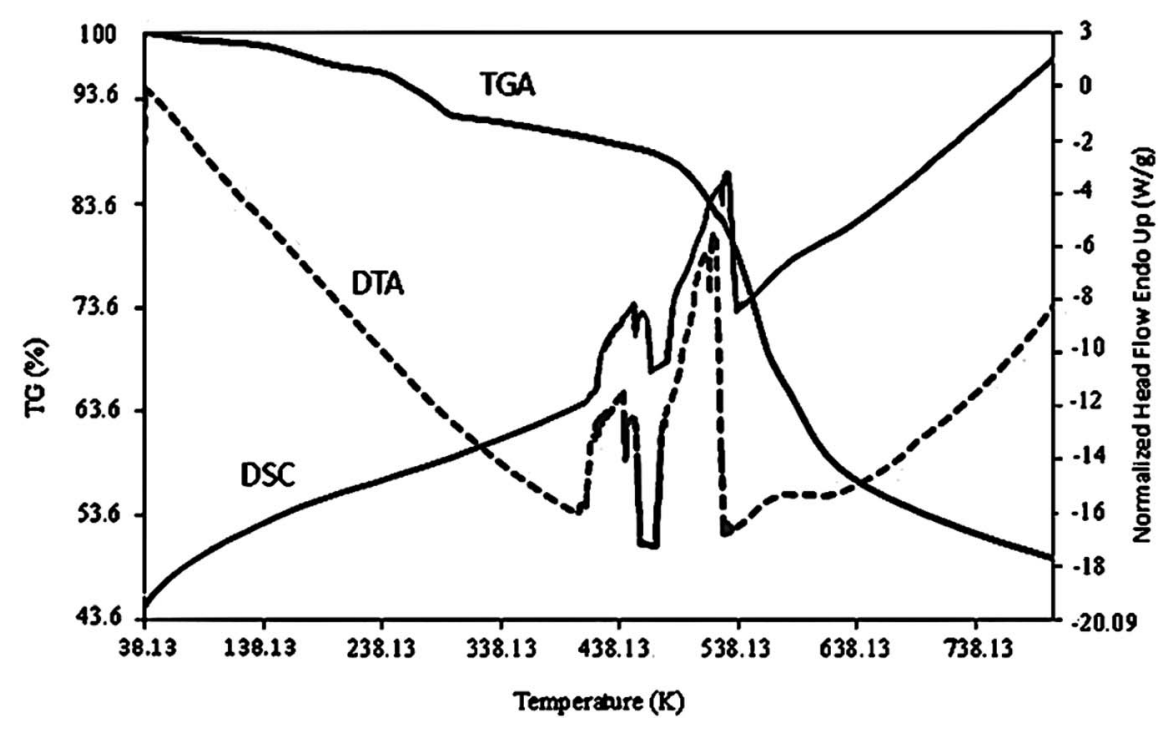

Fig. 10 TGA, DSC, and DTA curves of Co-MOF-based ZIF-67 ( $\mathrm{SO}_{1}$ sample). 
the distribution of a particular element without requiring the quantitative point analysis.

Further characterization techniques, including the TGA, DTA, and DSC curves, were performed on the as-prepared CoMOF-based ZIF-67 ( $\mathrm{SO}_{1}$ sample) (Fig. 10). It can be seen that the weight loss percent decrease to $200{ }^{\circ} \mathrm{C}$ is relevant to the removal of guest molecules and gas molecules (unreacted species). Weight loss in the range of $250-500{ }^{\circ} \mathrm{C}$ can be relevant to the decomposition of imidazole ligands. This weight loss emerged as an exothermic peak in the range from 500 to $700{ }^{\circ} \mathrm{C}$ in the DTA curve. ${ }^{30}$ In the SPME method, since the adsorbent is exposed to the heat treatment, it is important that its structure is not decomposed at the intended temperature $\left(220{ }^{\circ} \mathrm{C}\right)$. In general, the thermogravimetric curves confirmed that the CoMOF-based ZIF-67 has good thermal stability during the extraction operations $\left(220^{\circ} \mathrm{C}\right)$.

The BET analysis was used to determine the specific surface area (BET isotherm), size, and empty volume of cavities (BJH), as shown in Fig. S6 and Table S2, ESI. $\dagger$ The as-synthesized sample tendency followed type I isotherm (Langmuir) as per the IUPAC classification. ${ }^{36}$ The pore size distribution for Co-
MOF-based ZIF-67 is mainly in the micropore range. The BET surface area for Co-MOF-based ZIF-67 ( $\mathrm{SO}_{1}$ sample) was $1528 \mathrm{~m}^{2}$ $\mathrm{g}^{-1}$, along with a pore volume of $0.083 \mathrm{~cm}^{3} \mathrm{~g}^{-1}$ and a mean pore diameter of $1.21 \mathrm{~nm}$.

\section{Applications of Co-MOF-based ZIF-67}

\subsection{Optimization of the parameters affected by the SPME method}

For enhancing the pre-concentration and extraction efficiency, extraction temperature and extraction time as the effective parameters on the proposed method were investigated and optimized.

4.1.1. Extraction temperature and time. Increasing the extraction temperature has an inverse effect for extracting the analyte molecules in the SPME method due to the exothermic process for the adsorption of the analyte molecules on the coated SPME wire. ${ }^{47}$ In this regard, extraction temperature as a pivotal role for the preconcentration of the analyte was studied. To investigate the introduced parameter, the tests were

(a)

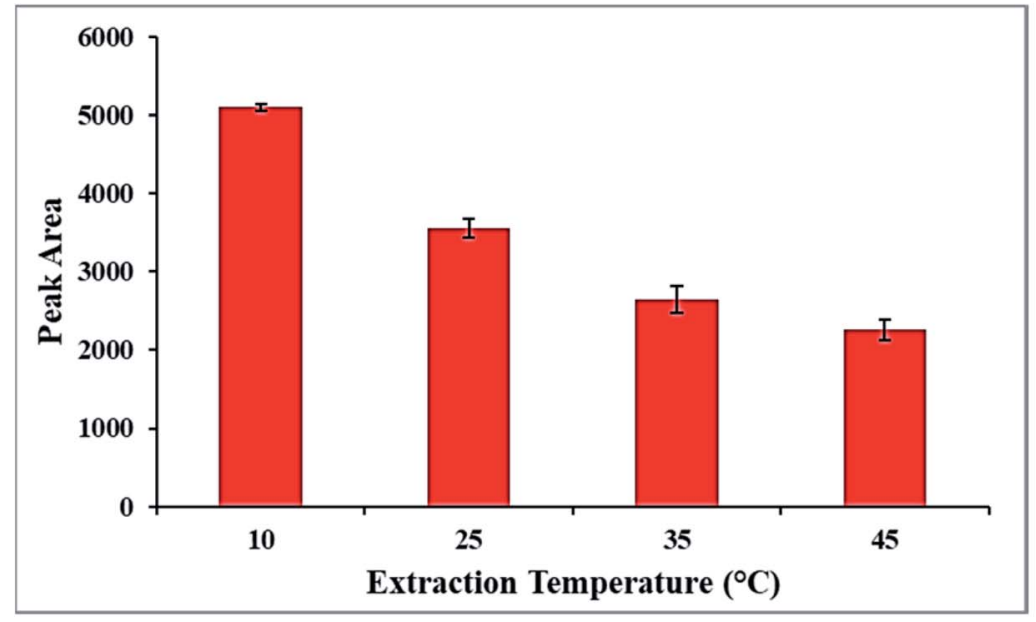

(b)

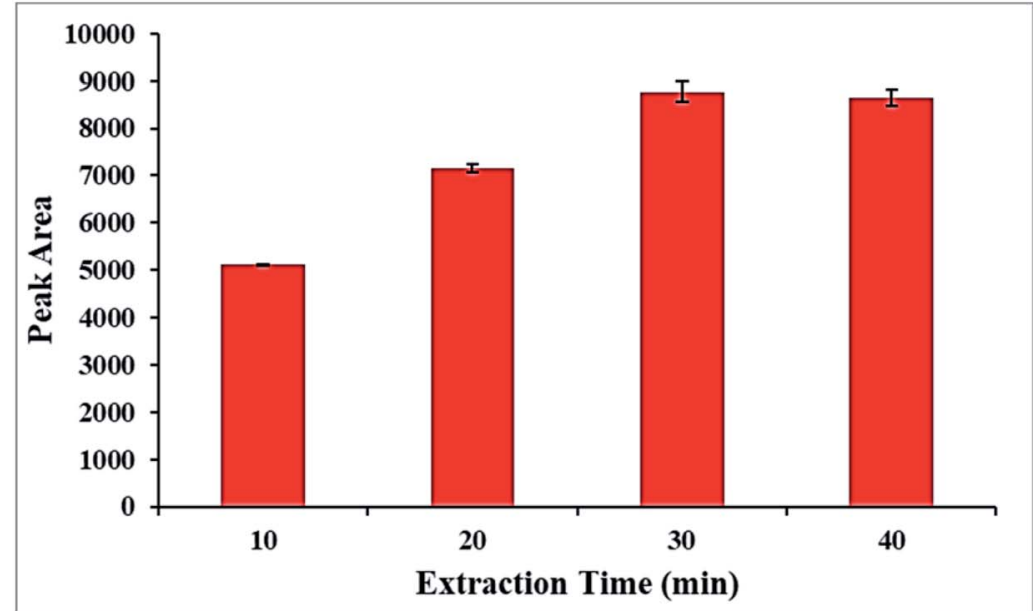

Fig. 11 (a) The effect of the extraction temperature (sample solution volume, $10 \mathrm{~mL}$; analyte concentration, $10.0 \mu \mathrm{g} \mathrm{L}{ }^{-1}$ ), (b) the effect of the extraction time on the extraction efficiency (sample solution volume, $10 \mathrm{~mL}$; analyte concentration, $10.0 \mu \mathrm{g} \mathrm{L}^{-1}$ ). 


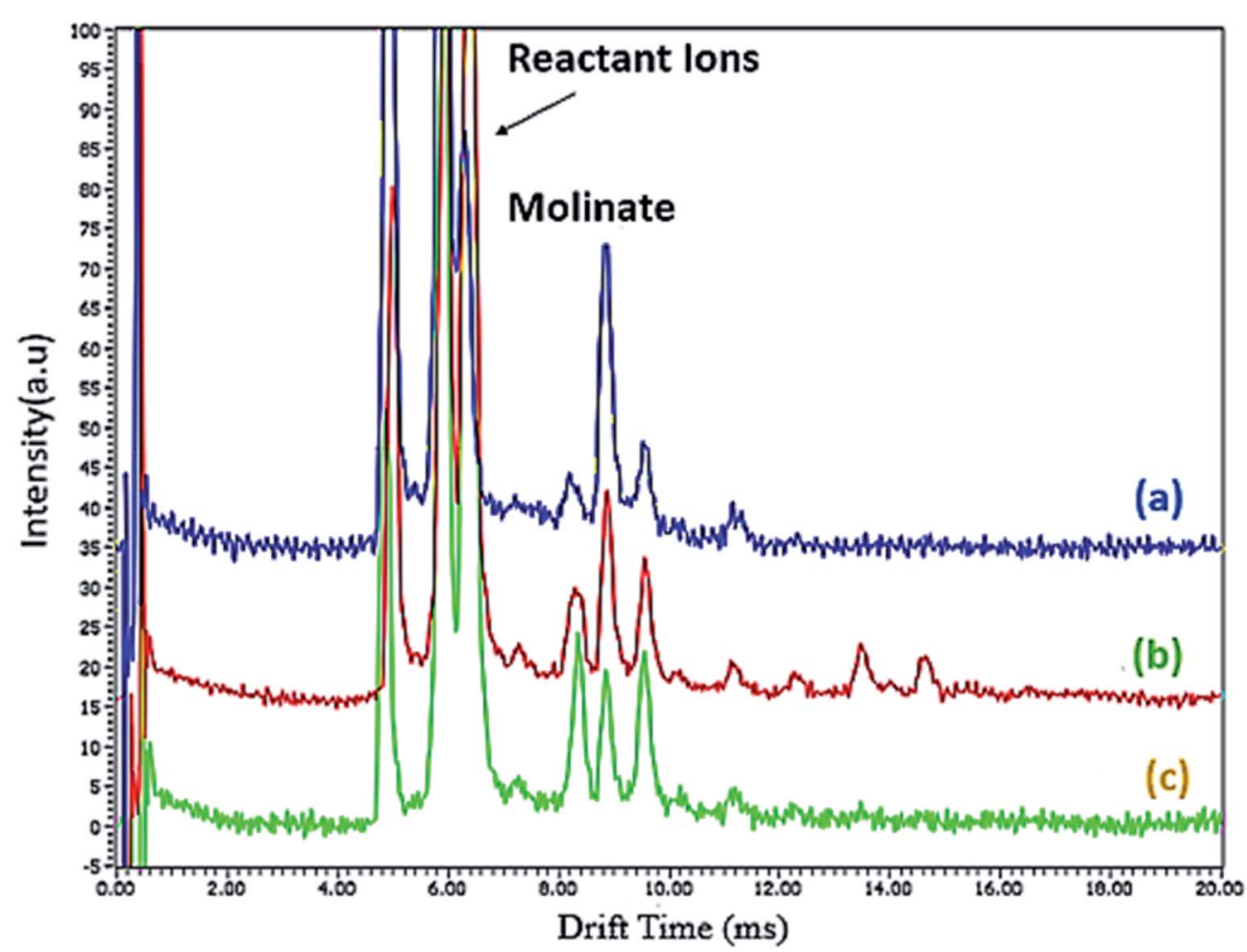

Fig. 12 Ion mobility spectra of extracted molinate molecules by different solvents (a) methanol, (b) methanol-water, and (c) water.

done at the extraction temperatures between $10{ }^{\circ} \mathrm{C}$ and $45{ }^{\circ} \mathrm{C}$. According to the acquired data, indicated in Fig. 11a, the temperature of $10{ }^{\circ} \mathrm{C}$ was chosen as the best optimized temperature for the next tests.

Besides, to obtain the equilibrium situation between the molinate solution and the Co-MOF-based ZIF-67 SPME wire in the SPME method,$^{48}$ the time of the analyte extraction between 10 and $40 \mathrm{~min}$ was investigated and optimized. According to Fig. 11b, the high extraction efficiency for extracting the molinate molecules was obtained at $30 \mathrm{~min}$.

4.1.2. Comparison of the extraction efficiency of the CoMOF-based ZIF-67 prepared using different solvents. To compare the extraction efficiency of the Co-MOF-based ZIF-67 synthesized using different solvents, including methanol, water, and methanol-water mixture, the ion mobility spectrometry test was investigated. Using water as a solvent, the extraction efficiency is low, which is attributed to the leaf-like morphology with a 2D multilayer structure. However, using a mixture of water and ethanol as a solvent for the synthesis of Co-MOF-based ZIF-67, the extraction efficiency is improved. However, because of the agglomerated structure, the extraction efficiency of molinate molecules does not increase optimally. Using methanol as a solvent, a remarkable increase in the extraction efficiency of molinate is observed, which is attributed to the rhombic dodecahedral morphology with a threedimensional porous structure, micro and meso cavities (Fig. 12). Based on the molinate structure and functional groups in the MOF surface, some interactions are present to adsorb the molinate, such as salt bridge interactions, including the hydrogen bonds and electrostatic interactions between the adsorbent and analyte. Furthermore, the linear dynamic range (LDR) and the determination coefficient were detected to be $0.5-20.0 \mu \mathrm{g} \mathrm{L}^{-1}$ and 0.9990 , respectively. In this regard, the limit of quantification (LOQ) and the limit of detection (LOD) were calculated as $0.5 \mu \mathrm{g} \mathrm{L}^{-1}$ and $0.15 \mu \mathrm{g} \mathrm{L}^{-1}$, respectively.

\section{Conclusions}

In summary, a collection of the Co-MOF-based ZIF-67 nanostructures with various morphologies are prepared by a simple method and under different reaction parameters, including reaction solvents, temperature, time, cobalt source, and different Hmim to cobalt ion molar ratios. In this study, CoMOF-based ZIF-67 has been used as an adsorbent fiber in the solid phase microextraction method to determine the molinate concentration (as a test compound) in the aqueous samples. In this method, an ion mobility spectrometer is used as the detection system. Sensitivity, simple apparatus, and quick analysis are counted as the advantages of this system. Also, two critical parameters, extraction time and temperature, were analyzed and optimized. This study demonstrates that methanol as a solvent brings the highest extraction efficiency compared to water or a mixture of water with methanol as a solvent. Using these optimized conditions, an LOD of $0.15 \mu \mathrm{g}$ $\mathrm{L}^{-1}$, LOQ of $0.5 \mu \mathrm{g} \mathrm{L}^{-1}$, determination coefficient of 0.9990 , and LDR of $0.5-20.0 \mu \mathrm{g} \mathrm{L}^{-1}$ were accomplished. The relative standard deviation (RSD) of the different fibers at the molinate concentration of $10 \mu \mathrm{g} \mathrm{L} \mathrm{L}^{-1}$ was obtained at $6 \%$. 


\section{Author contributions}

M. D. helped in preparing the material, characterization by different characterization techniques, and writing the manuscript. M. R. R. helped in the discussion and analytical characterization. M. T. J contributed to the characterization of the obtained materials and discussed the results. Furthermore, F. D. and A. E. S. designed the research, contributed to supervising the work, discussed the results, and wrote the manuscript. All the authors participated in writing, editing, and revising the manuscript.

\section{Conflicts of interest}

The authors declare no conflict of interest.

\section{Acknowledgements}

AES is currently on leave from CMRDI. The authors of the article would like to show their appreciation for the Isfahan University of Technology's financial support. Furthermore, AES is grateful for the National Research grants from MINECO, Spain, "Juan de la Cierva" [FJCI-2018-037717].

\section{References}

1 E. Malaj, K. Liber and C. A. Morrissey, Sci. Total Environ., 2020, 718, 134765.

2 O. C. Nunes, A. R. Lopes and C. M. Manaia, Appl. Microbiol. Biotechnol., 2013, 97, 10275-10291.

3 N. P. Shetti, S. J. Malode, D. Ilager, K. Raghava Reddy, S. S. Shukla and T. M. Aminabhavi, Electroanalysis, 2019, 31, 1040-1049.

4 X. Bo, J. Sun, Q. Mei, B. Wei, Z. An, D. Han, Z. Li, J. Xie, J. Zhan and M. He, Ecotoxicol. Environ. Saf., 2019, 191, 110175.

5 R. T. Ledari, J. Rahimi, A. Maleki and A. E. Shalan, New J. Chem., 2020, 44, 19827-19835.

6 C. Drees, A. Schütz, G. Niu, J. Franzke, W. Vautz and S. Brandt, Anal. Chim. Acta, 2020, 1127, 89-97.

7 A. Sorribes-Soriano, M. de la Guardia, F. A. Esteve-Turrillas and S. Armenta, Anal. Chim. Acta, 2018, 1026, 37-50.

8 X. Li, X. Yang, H. Xue, H. Pang and Q. Xu, EnergyChem, 2020, 2, 100027.

9 L. R. Redfern and O. K. Farha, Chem. Sci., 2019, 10, 1066610679.

10 M. Kalaj and S. M. Cohen, ACS Cent. Sci., 2020, 6, 1046-1057. 11 X. Du and M. Zhou, Chem. Eng. J., 2021, 403, 126346.

12 H. Y. Li, S. N. Zhao, S. Q. Zang and J. Li, Chem. Soc. Rev., 2020, 49, 6364-6401.

13 N. Ali, M. Bilal, A. Khan, F. Ali, H. Khan, H. A. Khan, K. Rasool and H. M. N. Iqbali, J. Mol. Liq., 2020, 318, 114273.

14 A. Barjola, J. Escorihuela, A. Andrio, E. Giménez and V. Compañ, Nanomaterials, 2018, 8, 1-17.

15 Y. V. Kaneti, S. Dutta, M. S. A. Hossain, M. J. A. Shiddiky, K. -L. Tung, F. -K. Shieh, C. -K. Tsung, K. C. -W. Wu and Y. Yamauchi, Adv. Mater., 2017, 29, 1-31.
16 L. Jin, J. Ye, Y. Wang, X. Qian and M. Dong, Fibers Polym., 2019, 20, 2070-2077.

17 I. Brekalo, D. E. Deliz, C. M. Kane, T. Friščić and K. Travis Holman, Molecules, 2020, 25, 25030633.

18 X. Guo, L. Kong, Y. Ruan, Z. Diao, K. Shih, M. Su, L. Hou and D. Chen, J. Colloid Interface Sci., 2020, 578, 500-509.

19 R. Taheri-Ledari, S. S. Mirmohammadi, K. Valadi, A. Maleki and A. E. Shalan, RSC Adv., 2020, 10(71), 43670-43681.

20 R. Taheri-Ledari, M. S. Esmaeili, Z. Varzi, R. EivazzadehKeihan, A. Maleki and A. E. Shalan, RSC Adv., 2020, 10(66), 40055-40067.

21 S. Feng, X. Zhang, D. Shi and Z. Wang, Front. Chem. Sci. Eng., 2020, 8, 1-17.

22 M. U. A. Prathap and S. Gunasekaran, Adv. Sustainable Syst., 2018, 2, 1800053.

23 A. Sławek, K. Roztocki, D. Majda, S. Jaskaniec, T. J. H. Vlugt and W. Makowski, Microporous Mesoporous Mater., 2020, 311, 110730.

24 J. Deng, Z. Dai and L. Deng, Ind. Eng. Chem. Res., 2020, 59, 14458-14466.

25 Y. Chen and S. Tang, J. Solid State Chem., 2019, 276, 68-74. 26 Q. Yang, R. Lu, S. S. Ren, C. Chen, Z. Chen and X. Yang, Chem. Eng. J., 2018, 348, 202-211.

27 X. Cao, X. Wang, M. Chen, F. Xiao, Y. Huang and X. Lyu, Sep. Purif. Technol., 2020, 8, 118062.

28 Y. Li, Y. Yang, D. Chen, Z. Luo, W. Wang, Y. Ao, L. Zhang, Z. Yan and J. Wang, Catalysts, 2019, 9, 2019.

29 N. Mostafazadeh, A. A. Ghoreyshi and K. Pirzadeh, Iran. J. Chem. Eng., 2018, 15, 27-47.

30 Z.-h. Zhang, J.-l. Zhang, J.-m. Liu, Z.-h. Xiong and X. Chen, Water, Air, Soil Pollut., 2016, 227, 471.

31 S. Wang, S. Zhang, X. Du, Y. Shen and Z. Ma, Adv. Mater. Sci. Eng., 2019, 2019, 9734984.

32 H. Ren, L. Zhang, J. An, T. Wang, L. Li, X. Si, L. He, X. Wu, C. Wang and Z. Su, Chem. Commun., 2014, 50, 1000-1002.

33 N. A. H. M. Nordin, S. M. Racha, T. Matsuura, N. Misdan, N. A. A. Sani, A. F. Ismail and A. Mustafa, RSC Adv., 2015, 5, 43110-43120.

34 M. Wang, J. Liu, C. Guo, X. Gao, C. Gong, Y. Wang, B. Liu, X. Li, G. G. Gurzadyana and L. Sun, J. Mater. Chem. A, 2018, 6, 4768-4775.

35 A. Ulu, J. Mater. Sci., 2020, 55, 6130-6144.

36 X. Li, X. Gao, L. Ai and J. Jiang, Chem. Eng. J., 2015, 274, 238246.

37 H. Liu, Y. Zhao, N. Li, X. Zhao, X. Han, S. Li, W. Lu, K. Wang and S. Du, J. Mater. Res. Technol., 2019, 8, 6289-6300.

38 B. Pattengale, S. Yang, J. Ludwig, Z. Huang, X. Zhang and J. Huang, J. Am. Chem. Soc., 2016, 138, 8072-8075.

39 Y. Li, Z. Jin and T. Zhao, Chem. Eng. J., 2020, 382, 123051.

40 X. Guo, T. Xing, Y. Lou and J. Chen, J. Solid State Chem., 2016, 235, 107-112.

41 X. Li, Z. Li, L. Lu, L. Huang, L. Xiang, J. Shen, S. Liu and D. -R. Xiao, Chem.-Eur. J., 2017, 23, 10638-10643.

42 A. N. El-Shazly, M. M. Rashad, E. A. Abdel-Aal, I. A. Ibrahim, M. F. El-Shahat and A. E. Shalan, J. Environ. Chem. Eng., 2016, 4, 3177-3184.

43 E. Leontidis, Curr. Opin. Colloid Interface Sci., 2002, 7, 81-91. 
44 D. Yamamoto, T. Maki, S. Watanabe, H. Tanaka, M. T. Miyahara and K. Mae, Chem. Eng. J., 2013, 227, 145150.

45 R. R. Kuruppathparambil, T. Jose, R. Babu, G.-Y. Hwang, A. C. Kathalikkattil, D.-W. Kim and D.-W. Park, Appl. Catal., B, 2016, 182, 562-569.
46 J. Qian, F. Sun and L. Qin, Mater. Lett., 2012, 82, 220-223.

47 W. A. Wan Ibrahim, H. Farhani, M. M. Sanagi and H. Y. Aboul-Enein, J. Chromatogr. A, 2010, 1217, 4890-4897. 48 M. T. Jafari, M. R. Rezayat and M. Mossaddegh, Talanta, 2018, 178, 369-376. 